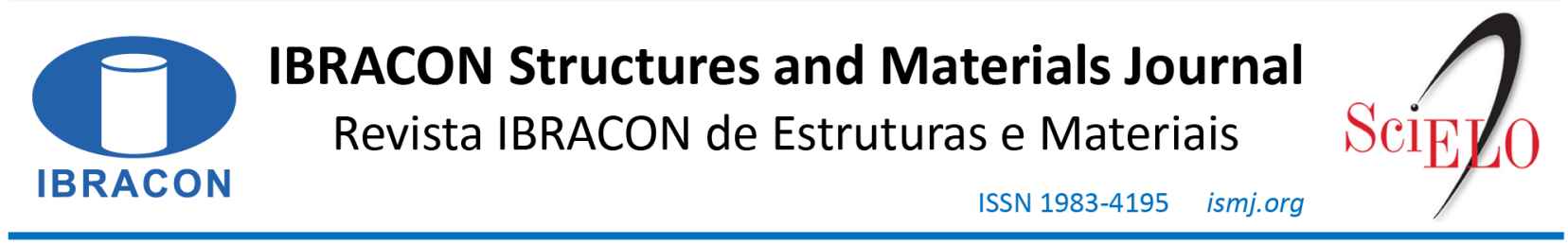

ORIGINAL ARTICLE

\title{
Application of MEMS accelerometer of smartphones to define natural frequencies and damping ratios obtained from concrete viaducts and footbridge
}

\author{
Uso de acelerômetros MEMS de smartphones para o conhecimento de frequências \\ naturais e taxas de amortecimento de viadutos e passarela em concreto \\ Jorge Dalmas Braido ${ }^{\mathrm{a}}$ (i) \\ Zacarias Martin Chamberlain Pravia ${ }^{\mathrm{a}}$ (D)

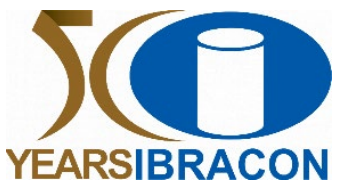

${ }^{a}$ Universidade de Passo Fundo - UPF, Programa de Pós-graduação em Engenharia Civil e Ambiental - PPGEng, Passo Fundo, RS, Brasil

Received 27 March 2021

Accepted 14 August 2021

\begin{abstract}
The continuous development of smartphones has garnered considered research attention owing to the possibility of its use in different engineering applications. MEMS accelerometers available on smartphones are useful for structural health monitoring. This study is aimed at determining the use of smartphones in the calibration and correction of the sampling rate for natural frequency and damping identification. Three concrete bridges were used in the case studies. The results indicate that smartphones can be used to understand some dynamic parameters.
\end{abstract}

Keywords: accelerometers, smartphones, calibration, MEMS, modal.

Resumo: a contínua evolução dos smartphones despertou o interesse da comunidade científica para aplicações deste aparelho em situações ligadas à engenharia estrutural. Em um caso mais específico, os acelerômetros MEMS que equipam aparelhos de telefonia móvel tem se mostrado úteis para a realização de monitoramentos da saúde estrutural SHM. O objetivo deste trabalho é apresentar o uso de MEMS do celular junto à calibração e correção da taxa de amostragem, as quais são necessárias para a identificação dos parâmetros modais de frequência natural e amortecimento. Os estudos de caso são três estruturas - dois viadutos em concreto armado e uma passarela em concreto protendido. Os resultados indicam que é possível utilizar este aparelho em casos onde é necessário o conhecimento de algumas propriedades dinâmicas ao alcance da mão.

Palavras-chave: acelerômetros, celular, calibração, MEMS, modal.

How to cite: J. D. Braido and Z. M. C. Pravia, “Application of MEMS accelerometer of smartphones to define natural frequencies and damping ratios obtained from concrete viaducts and footbridge," Rev. IBRACON Estrut. Mater., vol. 15, no. 2, e15206, 2022, https://doi.org/10.1590/S198341952022000200006

\section{INTRODUCTION}

Structural health monitoring (SHM) has undergone continuous development in civil infrastructure since the 1970s. This methodology, also known as St-Id, uses nondestructive methods composed of numerical models and experimental data to assess structural performance and aid in decisions regarding structural management and rehabilitation [1].

The evolution of SHM can also be seen on mobile sensors and wireless devices; for example, current smartphones are embedded with MEMS accelerometers. The use of wireless devices has become more appealing because it allows faster monitoring and is feasible in both public and private infrastructures.

Corresponding author: Jorge Dalmas Braido. E-mail: jorgebraido@gmail.com

Financial support: None.

Conflict of interest: Nothing to declare. 
MEMS accelerometers in smartphones have been studied [2]-[12]. In some of these studies they show monitoring using smartphones at different levels and situations, not necessarily from an SHM approach. These examples consider the adaptability and capability of smartphones.

When smartphones are used for SHM, concerns arise regarding data accuracy and calibration. According to Kuhlmann et al. [13], if the angle installation is in the range of $0.5^{\circ}$ to $3^{\circ}$, the data accuracy can be compromised. Moreover, civil structure strains are in the range of $-5^{\circ}-5^{\circ}[14]$. Therefore, in extreme situations where the device is installed incorrectly, the data from smartphones can correspond to an $8^{\circ}$ inclination. Data accuracy can also be jeopardized by incorrect device operation, resulting in the disposal of samples taken using the smartphone. Other error sources include inadequate manufacturing, voltage instability, and temperature effects [15].

The calibration of the MEMS accelerometer of a smartphone can be performed before any sample extraction and has simple computational steps that do not require special training [16]. The approach uses two special fixtures to record the acceleration in six positions, assuming constant gravitational force $(g)$. The position angle of the smartphone during calibration has been previously defined [14].

Moreover, smartphone sensors show low quality at a frequency range below $0.5 \mathrm{~Hz}$. This behavior is characteristic of colored noise, where the low-frequency spectrum is predominant [17]. Thus, a $1 \mathrm{~Hz}$ first-order natural frequency higher pass filter should be used to reduce unwanted frequency components [4], [18].

Another potential problem is that the smartphone's real sampling rate is lower than the target frequency [19]. This characteristic does not change the answers in the frequency peaks but modifies the amplitude values. A correction should be performed considering the ratio of the target frequency to the real frequency.

Although the mobile accuracy degree is lower than that of commercial accelerometers, their results are very similar [20]. Professional sensors have a $10^{-9} \mathrm{~g}$ resolution and measurement range below $\pm 1 \mathrm{~g}$, while smartphone resolution is in the range of 0.1 to $15 \mathrm{mg}$ with the measurement range of $\pm 4 \mathrm{~g}$ [5]. In this study, signals were assessed using the Root Mean Square (RMS) power data from before and after the filter application phases, and decibels are used to define attenuation or gain.

Smartphone mounting is performed by using double-sided tape to pin the smartphone to the structure to avoid local vibration during structural vibration measurement [3]. Stud mounting of accelerometers was used to analyze extremely high natural frequencies, as in the case of mechanical systems [21], [22]. Civil structures generally have very low natural frequencies. To avoid the interference from mounting the smartphone, a nondestructive method, such as structural adhesives or magnetic mounting, is ideal. This allows for more accurate assessments of structural damage, human comfort, and ground-borne noise applications; therefore, these techniques are more convenient and widely used.

The use of smartphones in monitoring activities is not restricted to one specific model or manufacturing company, which can expand the use of this device. Simple operation based on friendly applications is another reason for their implementation. Moreover, data can be saved, stored, and sent to data clouds, and some apps allow the definition of dynamic parameters, such as natural frequencies and damping rates, immediately after the measurements are taken.

According to Debona and da Silva [23], wired devices may cause involuntary accidents, such as the dragging of the device owing to pedestrian walking. To avoid these types of accidents, wireless devices must be implemented.

Studies have used different apps, such as the Accelerometer analyzer app developed by Mobile Tools [20], iDynamics app [5], and the phyphox app [12], in a controlled environment; however, in [24]. Phyphox was created to aid physics teaching using the smartphone sensors.

Because of the low costs associated with the use of MEMS accelerometers, they have been widely considered in the monitoring of civil structures. Considering that this type of device is found in most mobile devices, it can easily be applied to engineering issues.

In this study, one measurement point was adopted as nonofficial to discard commercial accelerometers. This configuration can present the influence of different vibration modes on the acceleration readings according to specific traffic conditions [25].

Three study cases located in Passo Fundo/RS were used to validate the process: two reinforced concrete bridges and a prestressed concrete footbridge. The bridges were $22.5 \mathrm{~m}$ in width and $36.0 \mathrm{~m}$ in length, with a common structural solution in Brazil: two cantilever girders simply supported with one span. The dimensions of the bridges were obtained from the structural design and retro analysis. The footbridge has a $\mathrm{T}$ cross-section and a length of $23.4 \mathrm{~m}$; although its dimensions were provided by the builder company, no additional information, such as cable positions, prestress force magnitude, or concrete strength class, was supplied. To verify the experimental dynamic parameters, finite element models and literature values were used as references.

Among the study cases, a minimum degree of comfort must be attained for the footbridge. Researchers and design standards have provided natural frequency values that guide this study. For instance, concrete footbridges with a span 
length of $23 \mathrm{~m}$ have a natural frequency in the range of $3.05-5.05 \mathrm{~Hz}$ [26]; natural frequencies higher than $5 \mathrm{~Hz}$ do not demand deeper evaluation related to pedestrian effects [27]; according to the Brazilian concrete standard [28], critical natural frequency $\left(f_{\text {crit }}\right)$ should be $4.5 \mathrm{~Hz}$ and reach a design stage of $\left(f>1,2 f_{\text {crit }}\right)$ vertical natural frequencies lower than $5 \mathrm{~Hz}$ should be avoided [29]; and finally, natural frequencies should be higher than $2 \mathrm{~Hz}$, which is the natural frequency of human walking [30].

In the case of the footbridge, its maximum damping ration is $1.7 \%$ [30]. Low damping ratios can vary in the range of $0.5 \%-1 \%[26]$.

In the case of bridges, natural frequencies are directly related to the span length [30]. The damping ratios cannot exceed $2 \%$. In the case of simply supported, reinforced concrete bridges, damping should not exceed $3.5 \%$ [31].

The goal of this study was to demonstrate the use of a smartphone in infrastructure monitoring. The steps for calibration and frequency sampling rate correction are explained by considering the natural frequency and damping ratios from the case study definitions. To verify the results, numerical models were created obeying the real dimensions obtained from the structural designs and the national standard of the material properties [28], [32]. In addition, this paper presents a high-pass filter application. The authors have only defined two angles for calibrating the vertical positions related to the gravitational force axis: first, with the screen upward, and the second, with the screen upsidedown.

The results showed that it is feasible to define the dynamic parameters from the case studies. However, smartphone limitations must also be considered. Thus, an indication of the behavior of the dynamic parameters can be reached with the MEMS accelerometers of smartphones in a simplified manner.

\section{MATERIALS AND EXPERIMENTAL PROGRAM}

\subsection{Measurement points}

Figure 1 shows the measurement points used in the case studies and smartphone positions. As shown in Figure 1a, the smartphone's position had already been identified, and ' $X$ ' represents the vandal load application point on the footbridge. In Figure 1b, the smartphone's position on the bridges has already been identified.

The excitation force on the footbridge was exerted by one person jumping over three different points: 1/2 L, 1/4 L, and 3/4 L. This excitation force is known as the vandal load [33] and was used because of the low population density (people $/ \mathrm{m}^{2}$ ) and the difficulty in exciting the footbridge. The jumps were performed only once at a point. Although the continuous jumping over the structure is an application of forced excitation force, the vibration source was applied only once over the structure, and the vibration decreases until it reaches the resting state.

In the case studies, the measurement point was located at the middle of the bridge span. Measurement points closer to the boundary conditions exhibit higher stiffness than the central regions [34]. This is because superstructure and mesostructure elements interact and can influence the natural frequency values.

In the bridges, the measurement point was located at the middle of the span, more precisely, on the lateral walkway.

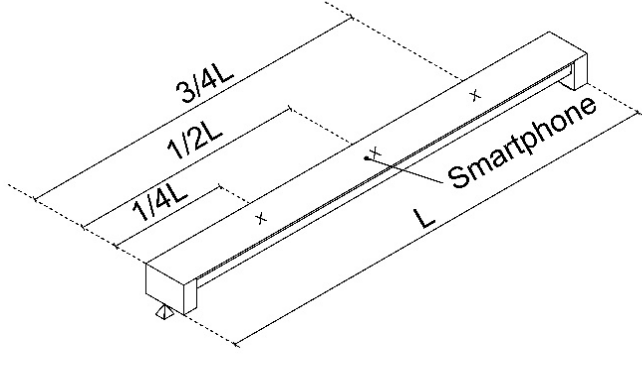

(a)

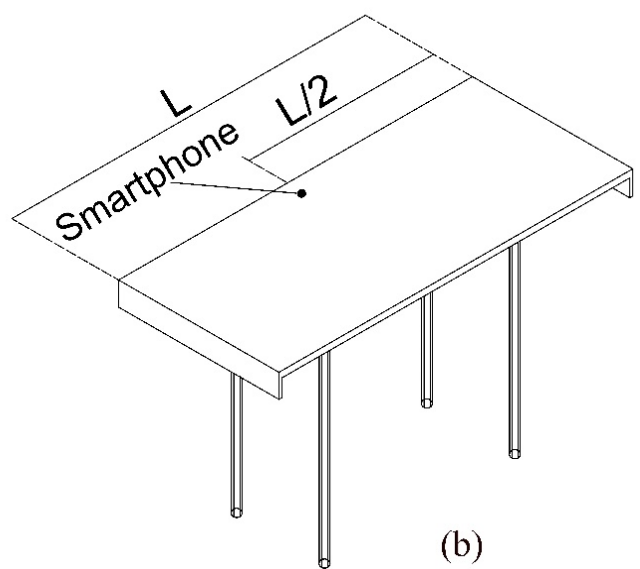

(b)

Figure 1: Measurement points on the (a) footbridge and (b) the bridges 
Figure $2 \mathrm{a}$ shows the total length of the footbridge and Figure $2 \mathrm{~b}$ shows its $\mathrm{T}$ cross-section on AA'.

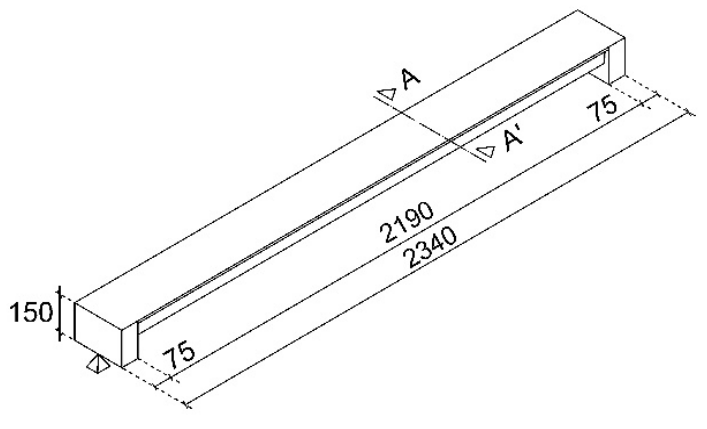

(a)

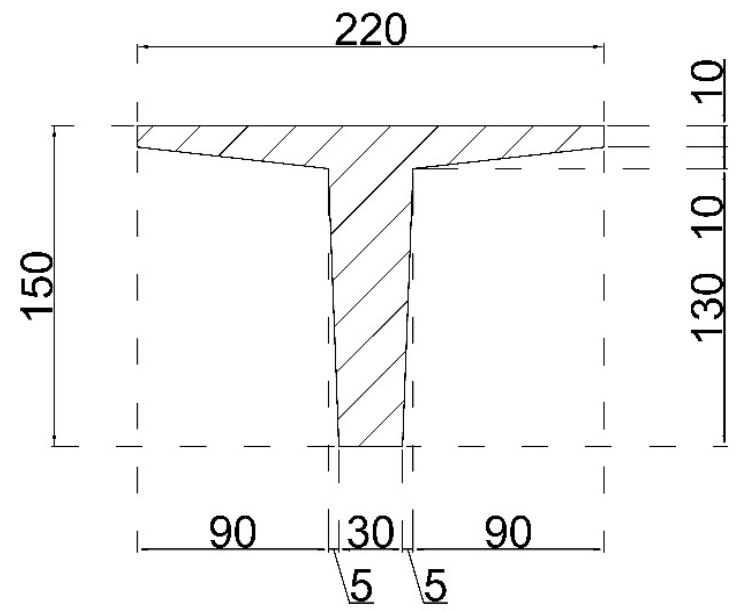

(b)

Figure 2: Footbridge length and cross-section (dimensions in centimeters).

\subsection{Materials}

The vibration test was performed using a Motorola Moto Z Force 2 smartphone, which has an LSM6DSM accelerometer with a $0.0023956299 \mathrm{~m} / \mathrm{s}^{2}$ resolution and a $428 \mathrm{~Hz}$ sampling rate.

This accelerometer can be used for vibration monitoring [35], and can function at $0.65 \mathrm{~mA}$, be used to record the triaxial acceleration, . In addition, it operates in the temperature range of $-40-+85^{\circ} \mathrm{C}$.

In this study, we used the Vibration Alarm app, developed and distributed for free by MobileTools, because it can record and store acceleration data. The version used in this study has four different sampling rates, namely 7, 27, 33, and $428 \mathrm{~Hz}$; sampling rate of $428 \mathrm{~Hz}$ was used in this study.

Acceleration data processing was performed using Microsoft Excel and Scilab, through which we selected the acceleration data, its processing, and the definition of the dynamic parameters. ANSYS Mechanical APDL 2020 R2 Academic was used to create finite element models.

\subsection{Methods}

\subsubsection{Extraction data}

Six data extractions were performed for each case. For bridges, the samples were $5 \mathrm{~min}$ in length. The beginning of the vibration test did not follow any special traffic conditions. On the footbridge, the samples have a shorter duration following jump execution. The smartphone was mounted using a double-sided tape on the back of the smartphone. Thus, during the vibration test, the smartphone was oriented such that its screen was in the upward direction.

\subsubsection{Calibration}

The calibration was performed using two fixtures created in a lathe machine using industrial nylon, with dimensions to couple the phone during the calibration operation. Using this apparatus, the smartphone's alignment is guaranteed to be in the three orthogonal axes: X, Y, and Z. The fixtures allowed the touchscreen to remain operable. Figure 3 shows the smartphone and the fixtures used in the calibration. 


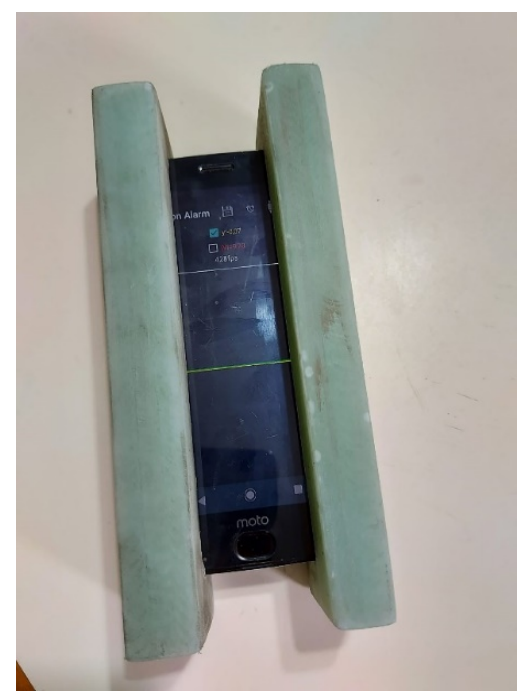

Figure 3: Smartphone during calibration

The calibration explores the fact that the gravitational force, $g$, is constant for a resting sensor. The method determines six positions for smartphone placement: three with positive gravitational force and three with negative gravitational force. In each position, one axis reads the acting $g$ force. Figure 4 shows the six positions of the smartphone during calibration.

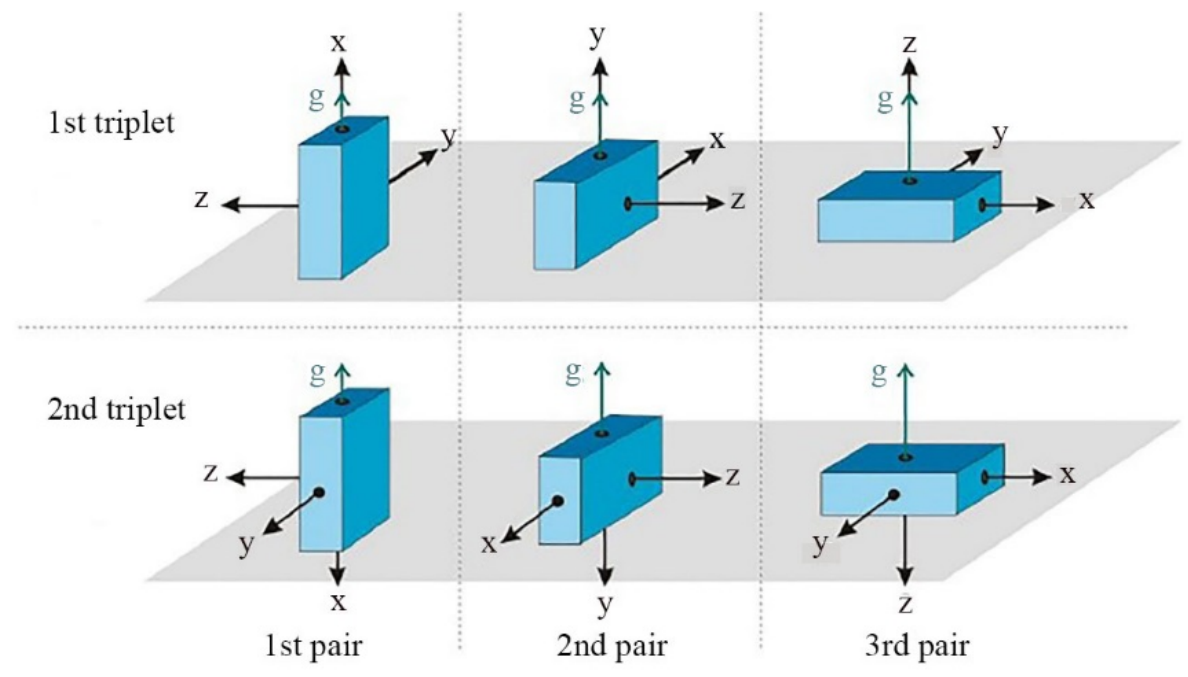

Figure 4: Calibration method [16]

Twelve calibration parameters were defined from the calibration matrix, Cs, and zero-level offset $a_{0}$ to correct the acceleration values from the case studies. This method performs static compensation, which is considered a source of invariant time errors.

The calibration matrix, $\mathrm{Cs}$, is obtained through the combination of the positive and negative static acceleration matrices, $\mathrm{A}_{\mathrm{s}^{+}}$and $\mathrm{A}_{\mathrm{s}^{-}}$. These are $3 \times 3$ matrices, and they assume the same value as the mean acceleration values for each axis. The calibration matrix, Cs, is defined as,

$C_{S}=2\left(A_{S+}-A_{S-}\right)^{-1}$ 
where $C s$ is the calibration matrix $\left(\mathrm{m} / \mathrm{s}^{2}\right), A_{s^{+}}$is the static matrix considering a positive force, $g$, acting on the $\mathrm{X}$, $\mathrm{Y}$, and $\mathrm{Z}$ axes on the first set of calibration measurements $\left(\mathrm{m} / \mathrm{s}^{2}\right)$, and $A_{s-}$ is the static matrix considering a negative force, $g$, acting on axes $\mathrm{X}, \mathrm{Y}$, and $\mathrm{Z}$ on the second set of calibration measurements $\left(\mathrm{m} / \mathrm{s}^{2}\right)$.

The other parameters were obtained from the zero-level offset $a_{0}$, which requires the determination of the $\mathrm{A}_{0}$ matrix. Each $\mathrm{A}_{0}$ matrix column presents a zero-level offset $a_{0}$ obtained from a measurement pair. The $\mathrm{A}_{0}$ matrix is determined as follows:

$$
A_{0}=\frac{A_{S+}+A_{S-}}{2}\left(\mathrm{~m} / \mathrm{s}^{2}\right)
$$

The zero-level offset $\mathrm{a}_{0}$ is

$$
a_{0}=\frac{\left(A_{s+}+A_{s-}\right) i}{6}\left(\mathrm{~m} / \mathrm{s}^{2}\right)
$$

where $i$ is a $3 \times 1$ order vector of 1 .

The Cs matrix and $a_{0}$ parameter are inserted in equation 4 to correct the acceleration data from the case studies:

$$
a=C_{S}\left(a_{S}-a_{0}\right)
$$

where $a$ is the corrected acceleration $\left(\mathrm{m} / \mathrm{s}^{2}\right), C s$ is the calibration matrix $\left(\mathrm{m} / \mathrm{s}^{2}\right), a_{s}$ is the acceleration data from the structure $\left(\mathrm{m} / \mathrm{s}^{2}\right)$, and $a_{0}$ is the zero-level offset $\left(\mathrm{m} / \mathrm{s}^{2}\right)$.

In this study, only the data from vertical acceleration was corrected. The calibration samples had a one-minute length and 28,597 acceleration reads for each axis. Better calibration results would be obtained if the calibration samples were larger.

\subsubsection{Angle between the smartphone vertical axis and gravitational acceleration vector during calibration}

Angles were defined using the gravity vector and vertical axis acceleration. The inverse tangent function provides more accuracy [14].

Angles refer to the calibration step, and their purpose is to verify the effectiveness of the special fixtures that were built for this application. Considering that only the vertical axis acceleration is used in the processing phase, the angles used in this study are those related to the positive and negative vertical positions. This assumes that the calibration matrix and the zero-level offset are known, because their values are combined from the other two matrices. Angles from the mean acceleration are defined as

$$
\varnothing=\tan ^{-1} \frac{\sqrt{A_{x, o t}^{2}+A_{y, o t}^{2}}}{A_{z, o t}}
$$

where $\varnothing$ is the angle between the smartphone vertical axis and the gravitational acceleration vector in degrees $\left(^{\circ}\right)$, and $A_{\mathrm{x}, \mathrm{ot}}, A_{\mathrm{y}, \mathrm{ot}}$, and $A_{\mathrm{z}, \mathrm{ot}}$ are the acceleration means obtained from the vertical positions extracted during calibration $\left(\mathrm{m} / \mathrm{s}^{2}\right)$.

\subsubsection{Data processing}

A Butterworth High-Pass filter (BHP), which has a $1 \mathrm{~Hz}$ natural frequency and one pole, was applied to minimize the influence of the colored noise influence. This is the simplest filter configuration [36].

The signal power was defined from the relation between RMS [37] using the ratio before and after the application of the BHP filter. This procedure gives a result in voltage, which is later converted into decibels and defines the attenuation or grain of the signal. 
Peak picking was used to identify the natural frequencies. This method was applied owing to the simplicity and fastness of the application, but it is very difficult to determine the natural frequency with a greater degree of accuracy [38].

The damping ratios were defined using the logarithmic decrement method in the time domain. The property's definition was based on the visual recognition of the logarithmic decrement pattern in one of the acceleration peaks. Eleven acceleration peaks were used to minimize identification errors [39].

\subsubsection{Sampling rate corretion}

This correction is necessary because of the measurement quality variation, which considers the accelerometer's sampling rate and sampling delay [19]. Real sampling can be defined from timestamp analysis, total time, and acceleration readings in one sample. The sampling correction factor, $k_{\text {correction, }}$ considers the target and achieved sampling rates of the smartphone:

$$
k_{\text {corrction }}=\frac{f_{\text {sachieved }}}{f_{\text {starget }}}
$$

where $k_{\text {correction }}$ is the sampling rate correction ratio, $f_{\text {achieved }}$ is the real sampling rate, and $f_{\text {target }}$ is the smartphone app sampling rate.

The correction is performed by multiplying the amplitude values that are already available in the frequency domain. Real frequency, $f_{\text {real }}(\mathrm{Hz})$, is defined as

$$
f_{\text {real }}=f_{\text {identified }} \times k_{\text {correction }}
$$

where $f_{\text {identified }}$ is the natural frequency identified by the sensor $(\mathrm{Hz})$.

\subsubsection{Numeric models}

The meshes of the numeric models of the study cases were defined with the aid of mesh tests, which started with a size of $50 \times 50 \mathrm{~cm}$, decreasing $5 \mathrm{~cm}$ each time. The testing was stopped when the modal parameters did not show a significant variation. Moreover, meshes obeyed the nodal limitations from the student version and avoided mesh errors.

The numerical model of the footbridge was a solid created in two stages: first, the T cross-section was built from the PLANE183 element. Second, the area was extruded longitudinally, transforming PLANE183 into SOLID186. This element is a $3 \mathrm{D}$ element with 20 nodes and exhibits a quadratic displacement behavior. It has three degrees of freedom per node: translation in the $\mathrm{x}, \mathrm{y}$, and $\mathrm{z}$ directions [40].

The material properties of the footbridge were a $33 \mathrm{GPa}$ Young's modulus, with a density of $2500.00 \mathrm{~N} / \mathrm{m}^{3}$. The footbridge is simply supported at the ends, and transversal displacement is avoided through the boundary conditions in the flange. Tension stress was not considered. Mesh size was $15 \times 15 \mathrm{~cm}$.

Bridges V1 and V2 were created from shell elements using SHELL181. The material properties of the V1 bridge have a Young's modulus of $25 \mathrm{GPa}$ according to Brazilian concrete standard correlations [28], with a density of 2533.58 $\mathrm{N} / \mathrm{m}^{3}$, which considers the pavement depth, New-Jersey concrete barrier, railings, girders, beams, and decks. Simply supported boundary conditions were applied to the nodes that matched the abutments. The boundary conditions avoided transverse displacements on the first and last transverse beams. Mesh size was $15 \times 15 \mathrm{~cm}$.

The material properties of the V2 bridge were a $20 \mathrm{GPa}$ Young's Modulus and $2536.78 \mathrm{~N} / \mathrm{m}^{3}$ density, considering their masses as existing, as done previously in the other study cases. The boundary conditions and mesh size are the same as those applied at the V1 bridge. The Poisson's ratio was 0.2 .

\section{RESULTS AND DISCUSSION}

\subsection{Calibration}

Calibration was performed on a planar surface. The Cs calibration matrix results are as follows: 
$C_{S}=\left[\begin{array}{lll}z_{1} & y_{1} & x_{1} \\ z_{2} & y_{2} & x_{2} \\ z_{3} & y_{3} & x_{3}\end{array}\right]=\left[\begin{array}{ccc}0.1017656 & 0.0006339 & -0.0003295 \\ -0.0003608 & 0.101254 & 0.0004612 \\ 0.0045794 & -0.0009603 & 0.1031238\end{array}\right]$

The zero level offset $\mathrm{a}_{0}$ was

$a_{0}=\left[\begin{array}{c}z a_{0} \\ y a_{0} \\ x a_{0}\end{array}\right]=\left[\begin{array}{l}-0.0521225 \\ -0.0093539 \\ -0.0224103\end{array}\right]$

The Cs and $\mathrm{a}_{0}$ matrices were placed to correct the acceleration data from the study cases.

\subsection{Angles between the smartphone vertical axis and gravitational force during the calibration process}

The angle obtained with the positive position with the screen upward was:

$$
\varnothing=\tan ^{-1} \frac{\sqrt{(-0.0765406)^{2}+(-0.043384)^{2}}}{9.7588723}=0.5165^{\circ}
$$

The angle obtained with the negative position with the screen upside-down was:

$$
\varnothing=\tan ^{-1} \frac{\sqrt{(0.0458722)^{2}+(-0.1067092)^{2}}}{-9.8908458}=-0.6728^{\circ}
$$

As shown above, the angles are lower than $1^{\circ}$. However, values greater than $0.5^{\circ}$ can influence the vibration data [13]. Therefore, the fixtures require further improvement, or the manufacturing method may need to be altered to yield a higher level of accuracy.

\subsection{Natural frequency correction}

Text files from the acceleration app were analyzed. The timestamp identification was not properly discovered because the app only presented the first millisecond algorithm. Thus, for a $428 \mathrm{~Hz}$ sampling rate, the timestamp was $0.002336 \mathrm{~s}$. In the text file, only the " 2 " algorithm is presented.

In the same text file, the timestamp failed to create an algorithm equal to 3 in several readings. Therefore, the timestamp that considers this millisecond algorithm can vary in the range between $255 \mathrm{~Hz}$ and $0.003922 \mathrm{~s}$ to $333 \mathrm{~Hz}$ and $0.003033 \mathrm{~s}$.

Data processing was performed with both timestamps, but they did not change the resultant natural frequency from the study cases. Sampling rates vary from the $428 \mathrm{~Hz}$ sampling rate from a range of $18.69 \%$ to $8.88 \%$ for $348 \mathrm{~Hz}$ to $390 \mathrm{~Hz}$, respectively. This behavior is expected because the natural frequency correction remains the same [19]. The results shown in this study refer to a sampling rate of $390 \mathrm{~Hz}$.

The results show that the sampling rate decreases after each sample in $0.07 \%$.

\subsection{Experimental vibration parameters}

The mean natural frequency obtained from the footbridge was $4.90 \mathrm{~Hz}$. The difference between the highest and lowest natural frequencies was $2.41 \%$. An additional vibration mode was identified to be closer to $35 \mathrm{~Hz}$.

The mean footbridge damping ratio was $1.32 \%$. The results vary between the ranges of $1 \%$ and $1.7 \%$; this damping range is greater than the lowest damping e, which is lower than the maximum damping. Therefore, the damping obtained in this study is acceptable. 
The footbridge's natural frequency is greater than $2 \mathrm{~Hz}$ [30], [26]. However, it requires a deeper evaluation [27]. Moreover, it does not meet specifications [28], [29]. Figure 5 shows the footbridge samples in the time domain after the BHP filter application in (a), frequency domain in (b), and samples for damping estimation in (c). Acceleration peaks refer to the execution of one jump, with $0.08 \mathrm{~m} / \mathrm{s}^{2}$ as the highest value. The power spectral density (PSD) showed a frequency peak close to $4.9 \mathrm{~Hz}$ and another with a dip close to $35 \mathrm{~Hz}$.



(a)

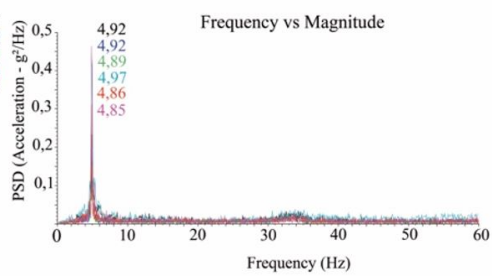

(b)

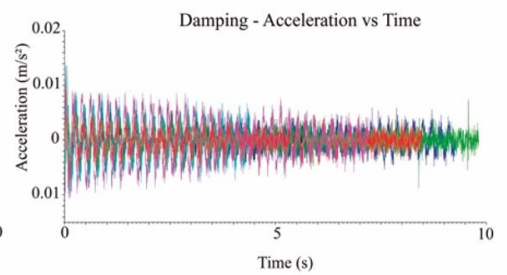

(c)

Figure 5: Footbridge accelerations recorded and PSD

Table 1 lists the experimental results of the footbridge. RMS showed lower results after the application of the filter and of the attenuations of -4 and $-9 \mathrm{~dB}$, the minimum and maximum values, respectively, between the six samples.

Table 1: Footbridges' experimental results

\begin{tabular}{ccccc}
\hline Sample & Excitation source point & $\begin{array}{c}\text { sampling frequency } \\
(\mathbf{H z})\end{array}$ & $\boldsymbol{\xi}(\mathbf{\%})$ & $\boldsymbol{f}(\mathbf{H z})$ \\
\hline 1 & $1 / 2 \mathrm{~L}$ & 389.72 & 1.64 & 4.92 \\
\hline 2 & $3 / 4 \mathrm{~L}$ & 389.58 & 1.58 & 4.92 \\
\hline 3 & $1 / 4 \mathrm{~L}$ & 389.46 & 1.34 & 4.89 \\
\hline 4 & $1 / 2 \mathrm{~L}$ & 389.37 & 1.28 & 4.97 \\
\hline 5 & $3 / 4 \mathrm{~L}$ & 389.26 & 1.23 & 4.86 \\
\hline 6 & $1 / 4 \mathrm{~L}$ & 389.17 & 0.81 & 4.85 \\
\hline & & Mean & 4.32 & 0.90 \\
\hline & & Standard deviation & 0.298 & 0.044 \\
\hline
\end{tabular}

The mean natural frequency of the V1 bridge was $12.20 \mathrm{~Hz}$. The difference between the highest and lowest values was $4.86 \%$. The mean damping of the V1 bridge was $2.17 \%$. Damping fell between the range of $2 \%$ and $3.5 \%$ [30], [31].

Figure 6 shows the V1 bridge samples in the time domain that followed the BHP filter application in (a), frequency domain in (b), and samples for damping estimation in (c). The highest acceleration peak was $0.2 \mathrm{~m} / \mathrm{s}^{2}$. Moreover, it was possible to identify peaks closer to 17 and $35 \mathrm{~Hz}$.



(a)



(b)

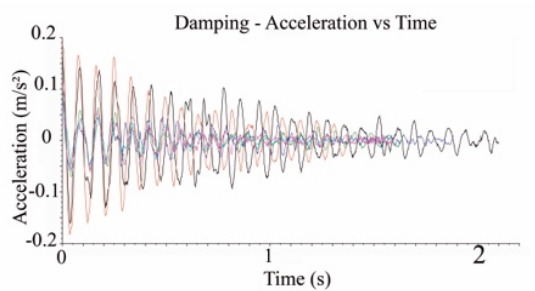

(c)

Figure 6: V1 bridge accelerations recorded and PSD 
Table 2 shows the V1 experimental results. RMS showed lower results after the application of the filter and the attenuations of -1 and $-2 \mathrm{~dB}$, minimum and maximum values, respectively.

Table 2: V1 experimental results

\begin{tabular}{cccc}
\hline Sample & Sampling frequency $\mathbf{( H z )}$ & $\boldsymbol{\xi}(\mathbf{\%})$ & $\boldsymbol{f}(\mathbf{H z})$ \\
\hline 7 & 390.61 & 1.09 & 12.44 \\
\hline 8 & 390.56 & 1.46 & 11.86 \\
\hline 9 & 390.44 & 2.58 & 11.84 \\
10 & 390.42 & 2.70 & 12.43 \\
11 & 390.24 & 2.58 & 12.39 \\
\hline 12 & 390.11 & 2.60 & 12.24 \\
\hline & Mean & 2.17 & 12.20 \\
\hline & Standard deviation & 0.702 & 0.282 \\
\hline
\end{tabular}

The V2 bridge exhibited different vibration modes with respect to its natural frequency. Two samples provided natural frequencies close to $5.30 \mathrm{~Hz}$, while the other four samples presented natural frequencies closer to $16.70 \mathrm{~Hz}$. These two natural frequency peaks can be easily identified among the acceleration samples from this bridge. These different natural frequency peaks from the same measurement points can cause the need to create additional modal identification methods or planning for additional measurement activities.

In addition to these two peaks, there were low peaks close to $25 \mathrm{~Hz}$. Owing to different results, the mean natural frequency, standard deviation, and variance are not presented. Figure 7 shows the V2 bridge samples in the time domain following the BHP filter application in (a), frequency domain in (b), and samples for damping estimation in (c). The highest acceleration peak was $0.06 \mathrm{~m} / \mathrm{s}^{2}$.

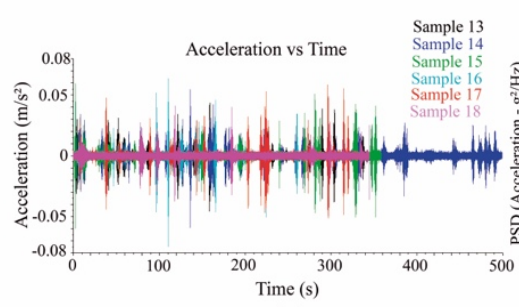

(a)

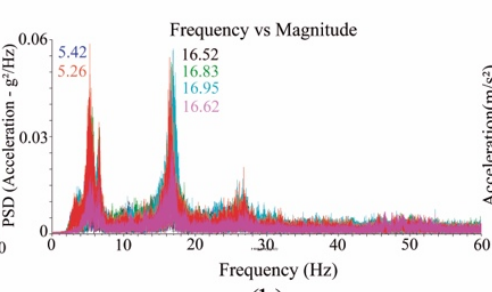

(b)

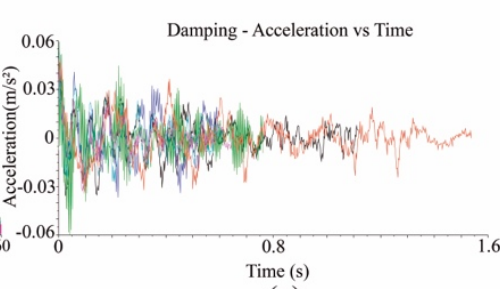

(c)

Figure 7: V2 bridge accelerations recorded and PSD

Table 3 shows the V2 experimental results. RMS showed lower results after the application of the filter and of the attenuations of -4 and $-8 \mathrm{~dB}$, minimum and maximum values, respectively.

Table 3: V2 experimental results

\begin{tabular}{cccc}
\hline Samples & Sampling frequency $\mathbf{( H z})$ & $\boldsymbol{\xi}(\mathbf{\%})$ & $\boldsymbol{f}(\mathbf{H z})$ \\
\hline 13 & 390.57 & 1.62 & 16.52 \\
\hline 14 & 390.36 & 2.04 & 5.42 \\
\hline 15 & 390.22 & 1.99 & 16.83 \\
\hline 16 & 390.13 & 1.66 & 16.95 \\
\hline 18 & 390.14 & 2.71 & 5.26 \\
\hline
\end{tabular}

\subsection{Numeric models}

For the footbridge, the first natural frequency presented is $4.01 \mathrm{~Hz}$ with a torsion modal shape; the second natural frequency is $6.99 \mathrm{~Hz}$, with a bending modal shape; the third natural frequency is $13.69 \mathrm{~Hz}$, with a lateral modal shape. 
The numerical footbridge model was created from a constant $\mathrm{T}$ cross section; however, this representation is a simplification. The real structure has a rectangular cross section above the abutments. In this case, the results were preliminary and therefore were not useful for comparisons or structural behavior assessments. Moreover, no prestressed normal force is considered in the model.

For the V1 bridge, the first modal shape is torsion, with a natural frequency of $11.50 \mathrm{~Hz}$; while the second modal shape was bending, with a natural frequency of $11.83 \mathrm{~Hz}$, and the third modal shape is torsion, presenting a natural frequency of $13.39 \mathrm{~Hz}$.

For the V2 bridge, the first modal shape is torsion, and its natural frequency is $6.60 \mathrm{~Hz}$; the second modal shape is bending, with a natural frequency of $6.84 \mathrm{~Hz}$. The third modal shape is lateral, with a natural frequency of $8.57 \mathrm{~Hz}$. The fourth bending modal shape has a natural frequency of $15.14 \mathrm{~Hz}$.

The numerical models applied in the study case were created following Brazilian concrete standards. Destructive tests were not performed. Moreover, it is possible to verify that there are simplifications in the models that can influence the behavior; thus, only preliminary observations should be made regarding dynamic parameters.

Figure 8 shows the modal shapes from the study cases, which had numerical natural frequencies closer to the experimental values. The modal shapes of the footbridges are as follows: (a) footbridge torsional modal shape, (b) V1 bending modal shape, and (c) V2 bending modal shape.

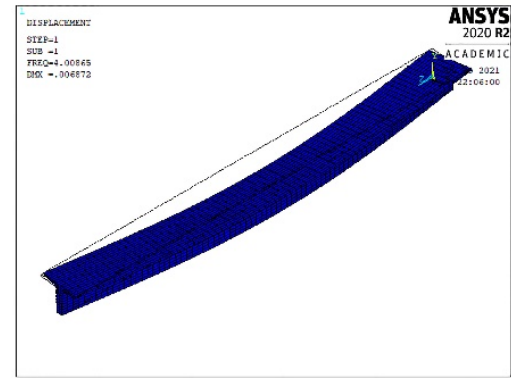

(a)

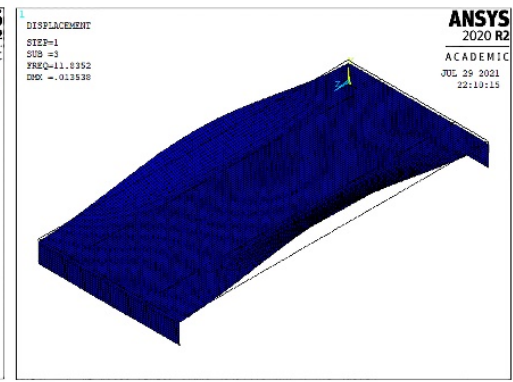

(b)

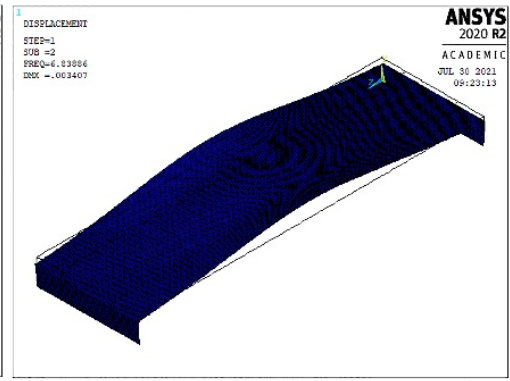

(c)

Figure 8: Study cases modal shapes

\subsection{Applied methods assessment}

The process assessment showed that the smartphone could define the natural frequencies and damping ratios in the case studies. However, calibration and sampling rate corrections are necessary.

The calibration method was straightforward and its execution was simple; the nylon industrial fixtures did not interfere with the touch screen, allowing the smartphone to operate normally. However, they did not guarantee precise readings; therefore, they did not present an acceptable degree of accuracy, which influenced the acceleration values.

The correction of the natural frequency resulted in a lower real sampling rate than the value indicated by the app. A negative aspect of the app refers to the timestamp presentation in the acceleration text file, which only provides the first millisecond algorithm. This feature can help one choose which app should be used: the ideal app should present the complete timestamp for each reading.

The experimental results from the study cases show that the footbridge and V1 bridge have similar natural frequencies to the numerical models. The footbridge also showed values that were close to those reported in previous literature. The V2 bridge showed two different natural frequencies and thus demands a different method of measurement or the modal identification method.

Attenuation was higher on the footbridge and on V2 than on V1, and it represented a greater noise reduction before the modal identification phase. Small vibration amplitudes are characteristics that indicate low signal quality [5]. Furthermore, structures with larger amplitudes result in better vibration parameter results when monitored with smartphones.

Numerical models, especially footbridges, are simplifications of the real structure and can represent non-official behavior. The obtained numerical values were close to the experimental values, but destructive tests were not performed to define the real properties of the materials. Thus, experimental vibration parameters prevail against the numerical results because they present the real behavior of the structure. 


\section{CONCLUSIONS}

The purpose of this study was to demonstrate the use of one smartphone for monitoring vibration activities. Three study cases were used: two bridges and one footbridge. Calibration and frequency sampling rate corrections were presented, and errors from accelerometer mounting and timestamp imperfections were minimized. After analyzing the results, we can conclude the following:

- A MEMS accelerometer embedded in a smartphone is an alternative for obtaining natural frequencies and damping ratios.

- The calibration method and sampling rate correction are essential because smartphones are not specifically designed for monitoring operations.

- The calibration results should improve the accuracy degree by using more precise calibration devices.

- Experimental vibration parameters are very similar to numerical results.

The smartphone was able to record acceleration data for natural frequencies and damping ratios after definition from study cases and corrections on calibration and sampling rate.

However, professional accelerometers should not be replaced by smartphones' MEMS accelerometers. This alternative could be useful for the engineering team if method limitations and corrections are considered before its application.

The use of the procedure shown in this paper, attests that the use of smartphones' MEMS accelerators can provide a less accurate alternative structural behavior definition at one's fingertips.

\section{REFERENCES}

[1] P. Cawley, "Structural health monitoring: closing the gap between research and industrial deployment," Struct. Health Monit., vol. 17, no. 5, 1225, 2018, http://dx.doi.org/10.1177/1475921717750047.

[2] Y. Yu, X. Zhao, and J. Ou "A new idea: mobile structural health monitoring using smart phones", in Int. Conf. Intell. Control Inf. Process., China, 2012. http://dx.doi.org/10.1109/ICICIP.2012.6391524.

[3] M. Feng, Y. Fukuda, M. Mizuta, and E. Ozer, "Citizen sensors for shm: use of accelerometer data from smartphones," Sensors, vol. 15, no. 2, pp. 2980-2998, 2015, http://dx.doi.org/10.3390/s150202980.

[4] Y. Yu et al., "J. Ou. "Initial validation of mobile-structural health monitoring method using smartphones," Int. J. Distrib. Sens. Netw., vol. 11, no. 2, 274391 2015, http://dx.doi.org/10.1155/2015/274391.

[5] A. Feldbusch, H. Sadegh-Azar, and P. Agne, "Vibration analysis using mobile devices (smartphones or tablets)," Procedia Eng., vol. 199, pp. 2790-2795, 2017, http://dx.doi.org/10.1016/j.proeng.2017.09.543.

[6] S. Castellanos-Toro, M. Marmolejo, J. Marulanda, A. Cruz, and P. Thomson, "Frequencies and damping ratios of bridges through Operational Modal Analysis using smartphones," Constr. Build. Mater., vol. 188, pp. 490-504, 2018, http://dx.doi.org/10.1016/j.conbuildmat.2018.08.089.

[7] A. B. Noel, A. Abdaoui, T. Elfouly, M. H. Ahme, A. Badawy, and M. S. Shehata, "Structural health monitoring using wireless sensor networks: a comprehensive survey," IEEE Commun. Soc., vol. 19, no. 3, pp. 1403-1423, 2017. http://dx.doi.org/10.1109/COMST.2017.2691551.

[8] T. J. Matarazzo, V. Vazifeh, S. Pakzad, P. Santi, and C. Ratti, "Smartphone data streams for bridge health monitoring," in Int. Conf. Struct. Dyn - EURODYN, Italy, 2017. http://dx.doi.org/10.1016/j.proeng.2017.09.203.

[9] T. J. Matarazzo et al., "Crowdsourcing bridge vital signs with smartphone vehicle trips", Comput. Soc. Appl. Phys., 2020.

[10] B. K. Muliterno, F. Muliterno Jr., and Z. M. C. Pravia, "Avaliação da irregularidade longitudinal do pavimento sobre pontes usando acelerações medidas por smartphones," Transportes, vol. 27, no. 2, pp. 182-193, 2019., http://dx.doi.org/10.14295/transportes.v27i2.1686.

[11] A. H. Alavi and W. G. Buttlar, "An overview of smartphone technology for citizen-centered, real-time and scalable civil infrastructure monitoring," Future Gener. Comput. Syst., vol. 93, pp. 651-672, 2019, http://dx.doi.org/10.1016/j.future.2018.10.059.

[12] K. G. Manikandan, K. Pannirselvam, J. J. Kenned, and C. S. Kumar, "Investigations on suitability of MEMS based accelerometer for vibration measurements," Mater. Today Proc., vol. 45, pp. 6183-6192, 2021, https://doi.org/10.1016/j.matpr.2020.10.506.

[13] T. Kuhlmann, P. Garaizar, and U. Reips, "Smartphone sensor accuracy varies from device to device in mobile research: the case of spatial orientation," Behav. Res. Methods, vol. 53, no. 1, pp. 22-33, 2021, http://dx.doi.org/10.3758/s13428-020-01404-5.

[14] J. Zhu, W. Wang, S. Huang, and W. Ding, "An improved calibration technique for MEMS accelerometer-based inclinometers," Sensors, vol. 20, no. 2, pp. 452, 2020, http://dx.doi.org/10.3390/s20020452.

[15] L. Cao and J. Chen, "Online investigation of vibration serviceability limitations using smartphones," Measurement, vol. 162, 107850, 2020, http://dx.doi.org/10.1016/j.measurement.2020.107850. 
[16] S. Stančin and S. Tomažič, "Time and computation-efficient calibration of MEMS 3D accelerometers and gyroscopes," Sensors, vol. 14, no. 8, pp. 14885-14915, 2014, http://dx.doi.org/10.3390/s140814885.

[17] S. V. Vaseghi, Advanced Digital Signal Processing and Noise Reduction, 2nd ed. England: John Wiley \& Sons, 2000.

[18] R. R. Ribeiro and M. R. Lameiras, "Evaluation of low-cost MEMS accelerometers for SHM: frequency and damping identification of civil structures," Lat. Am. J. Solids Struct., vol. 16, no. 7, e203, 2019, http://dx.doi.org/10.1590/1679-78255308.

[19] E. Ozer, D. Feng, and M. Q. Feng, "Hybrid motion sensing and experimental modal analysis using collocated smartphone camera and accelerometers," Meas. Sci. Technol., vol. 28, no. 10, 105903, 2017, http://dx.doi.org/10.1088/1361-6501/aa82ac.

[20] G. M. Guzman-Acevedo, G. E. Vazquez-Becerra, J. R. Millan-Almaraz, H. E. Rodriguez-Lozoya, A. Reyes-Salaza, and J. R. Gaxiola-Camacho, "GPS, accelerometer, and smartphone fused smart sensor for SHM on real-scale bridges," Adv. Civ. Eng., vol. 29, pp. 1-15, 2019, http://dx.doi.org/10.1155/2019/6429430.

[21] A. Miller, D. Sburlati, and D. Duschlbauer, “Accelerometer mounting: comparison of stud and magnetic mounting methods", in Hear to Listen: Acoust., Australia, 2018.

[22] A. Miyamoto, R. Kiviluoma, and A. Yabe, "Frontier of continuous structural health monitoring system for short \& medium span bridges and condition assessment," Front. Struct. Civ. Eng., vol. 13, no. 3, pp. 569-604, 2019, http://dx.doi.org/10.1007/s11709-018-0498-y.

[23] G. L. Debona and J. G. S. Silva, "Assessment of the dynamic structural behavior of footbridges based on experimental monitoring and numerical analysis," IBRACON Struct. Mater., vol. 13, no. 3, pp. 563-577, 2020, http://dx.doi.org/10.1590/s1983-41952020000300007.

[24] S. Staacks, S. Hütz, H. Heinke, and C. Stampfer, "Advanced tools for smartphone-based experiments: phyphox," Phys. Educ., vol. 53, no. 4, 045009, 2018, http://dx.doi.org/10.1088/1361-6552/aac05e.

[25] A. Elhattab, N. Uddin, and E. Obrien, "Extraction of bridge fundamental frequencies utilizing a smartphone mems accelerometer," Sensors, vol. 19, no. 14, pp. 3143, 2019, http://dx.doi.org/10.3390/s19143143.

[26] C. S. Oliveira, "Fundamental frequencies of vibration of footbridges in Portugal: from in situ measurements to numerical," Shock Vib., vol. 2014, pp. 1-22, 2014, http://dx.doi.org/10.1155/2014/925437.

[27] E. Caetano and A. Cunha, "Dynamic design of slender footbridges", in Proc. 2nd Int. Conf. Struct. Archit. - ICSA 2013, Guimarães, 2013. http://dx.doi.org/10.1201/b15267-154.

[28] Associação Brasileira de Normas Técnicas, Projeto de Estruturas de Concreto - Procedimento, NBR 6118, 2014.

[29] Service d'Études Techniques des Routes et Autoroutes. Footbridges: Assessment of Vibrational Behaviour of Footbridges Under Pedestrian Loading, 1st ed. Paris: Association Française de Génie Civil, 2006, pp. 1-127.

[30] H. Bachmann et al., Vibration Problems in Structures: Practical Guidelines, 1st ed. Basel: Birkhäuser Verlag, 1995. http://dx.doi.org/10.1007/978-3-0348-9231-5.

[31] P. Li, Y. Wang, B. Liu, and L. Su, "Damping properties of highway bridges in China," J. Bridge Eng., vol. 19, no. 5, 04014005, 2014, http://dx.doi.org/10.1061/(ASCE)BE.1943-5592.0000578.

[32] Associação Brasileira de Normas Técnicas, Projeto de Pontes de Concreto Armado e de Concreto Protendido - Procedimento, NBR 7187, 2003.

[33] E. Caetano, A. Cunha, and C. Moutinho, "Vandal loads and induced vibrations on a footbridge," J. Bridge Eng., vol. 16, no. 3, pp. 375-382, 2011, http://dx.doi.org/10.1061/(ASCE)BE.1943-5592.0000154.

[34] B. Wu, G. Wu, H. Lu, and D. Feng, "Stiffness monitoring and damage assessment of bridges under moving vehicular loads using spatiallydistributed optical fiber sensors," Smart Mater. Struct., vol. 26, no. 3, 035058, 2017, http://dx.doi.org/10.1088/1361-665X/aa5c6f.

[35] STMicroelectronics. LSM6DSM - iNEMO Inertial Module: Always-on 3D Accelerometer and 3D Gyroscope, 2017, pp. 1-126.

[36] G. Ellis, Control System Design Guide: a Practical Guide, 3rd ed. London, UK: Elsevier Academic Press, 2004.

[37] K. B. Ginn, Architectural Acoustics, 2nd ed. Nærum: Brüel \& Kjær, 1978.

[38] J. He and Z. Fu, Modal Analysis. 1st ed. UK: ButterWorth-Heinemann, 2001.

[39] D. J. Tweten, Z. Ballard, and B. P. Mann, "Minimizing error in the logarithmic decrement method through uncertainty propagation," J. Sound Vibrat., vol. 333, no. 13, pp. 2804-2811, 2014., http://dx.doi.org/10.1016/j.jsv.2014.02.024.

[40] ANSYS, Inc., ANSYS Mechanical APDL Element Reference. South Pointe: SAS IP, Inc., 2013.

Author contributions: JDB: conceptualization, acquisition, writing. ZMCP: conceptualization, acquisition, writing, supervision.

Editors: Samir Maghous, Guilherme Aris Parsekian. 